\title{
Una tabla de Martín Gómez “el Viejo” en el Museo del Prado
}

\author{
A painting by Martín Gómez "the Older" at the Prado Museum
}

Aída Padrón Mérida $(\dagger)^{*}$

Resumen: Se atribuye a un seguidor de Yáñez de la Almedina, Martín Gómez "el Viejo", una tabla del Museo del Prado, en controversia en cuanto a la participación del propio Yáñez en su ejecución. Además de las reflexiones sobre su autoría, se analizan las fuentes iconográficas y referentes visuales para la pintura.

El artículo fue realizado por Aída Padrón Mérida hacia 1993-1995, permaneciendo inédito tras su repentino deceso. Consideramos de interés dar a conocer sus reflexiones sobre esta pintura del museo del Prado.

Palabras clave: Pintura española, escuela valenciana, escuela conquense, siglo XVI, Yañez de la Almedina, Martín Gómez "el Viejo", iconografía.

Abstract: A painting at the Prado museum is attributed to a follower of Yáñez de la Almedina, Martín Gómez "the Older". The table was in controversy over the participation of Yáñez in its execution. In addition to the reflections on his authorship, the iconographic sources and visual references for painting are also analyzed.

The article was made by Aída Padrón Mérida towards 1993-1995, remaining unpublished after her sudden death. We consider it of interest to make known his reflections on this painting at the Prado Museum.

Key words: Spanish Painting, school of Valencia, school of Cuenca, $16^{\text {th }}$ century, Yañez de la Almedina, Martín Gómez "the Older", Iconography.

Recibido: 10/05/2017

\footnotetext{
* El presente artículo forma parte de una investigación materializada en un manuscrito inédito de Aida Padrón Mérida (†2000), conservado en el Instituto Moll. Centro de Investigación en pintura flamenca (Madrid), Fondo Padrón Mérida. Por su interés científico creemos conveniente su recuperación y publicación tal y como fue concebido, actualizando tan sólo aspectos historiográficos.
} 
a tabla de Cristo presenta a la Virgen a los redimidos del Limbo del Museo del Prado (O/T, 129,8 x 172,5 cm., no inv. P07618), se atribuye a Yánez de la Almedina en catálogo de venta de arte, en Madrid, en febrero de $1992^{1}$, fecha en la que la adquirió el museo con fondos del legado de Villaescusa con la intención de incrementar su colección de pintura valenciana del siglo XVI (Fig. 1). La pintura se expuso en las salas de la pinacoteca nacional dedicada a exposiciones temporales, y la autografía de Yánez se admitió expresamente en el catálogo de adquisiciones ${ }^{2}$, pero las gamas cromáticas, la factura lisa, el concepto de las sombras y los tipos, a pesar de su innegable ascendencia yañezca, revelan la escritura formal y pictórica de Martín Gómez "el Viejo", uno de los fieles epígonos del estilo conquense de Yánez. Adelanté esta atribución en referencias publicadas en 1993 y $1995^{3}$, con advertencia de un artículo a ser publicado con posterioridad, que se materializa en el presente trabajo.

Diego Angulo dio a conocer esta pieza, de episodios iconográficos yuxtapuestos, en una una breve y reveladora notificación ${ }^{4}$. Restituyó a Pablo de San Leocadio el San Miguel de Santo Domingo de Orihuela, hasta entonces inserto en la producción de Yánez, y argumentó la vinculación de este último con la obra que nos ocupa, en un momento de atribuciones caóticas que unificaban la producción de Llanos y Yánez e, incluso, la de otros pintores de estilo diametralmente opuesto al círculo valenciano. También Post, años más tarde, hará referencia a la pintura en su magna obra sobre la pintura española, atribuyéndola con alguna reserva a la mano del pintor almedinense, pensando en la colaboración de Miguel Esteve ${ }^{5}$. Siguiendo a los autores anteriores, la pintura en cuestión se registra ya en la reedición de la monografía sobre Yáñez de la Almedina de Garín Ortiz de Taranco, que estima la presencia de "colaboraciones secundarias"

\footnotetext{
${ }^{1}$ Pintura Antigua. Edmund Peel, Madrid, jueves 20 de febrero de 1992, no 4. En atención a la iconografía de la tabla, recurrente en la pintura levantina, la sitúan en la época valenciana del pintor almedinense. La ficha catalográfica de la casa de subastas da noticia también sobre la inclusión de la obra en el archivo fotográfico del Instituto Amatller de Barcelona (referencia R/M-438), con la atribución a Yáñez en la ficha correspondiente en letra manuscrita de José Gudiol. El soporte fue mutilado drásticamente no sólo en la zona alta, repintada probablemente con la intención de simular esta gratuita reducción, sino también en los laterales. Detrás de San Juan había otro personaje, del que aún persiste parte de la túnica y los pies. Los restos de un escudo pintado en el frontis de la mesa de altar (que hubiera aclarado el origen de la pintura y la estirpe del mecenas y su devoción) y la fragmentación de la corona de espinas, demuestran el corte de los paneles también en este borde. Esta salvaje intervención nos ha privado de datos reveladores sobre la historia externa del cuadro.
}

2 Felipe Vicente Garín Llombart, Un mecenas póstumo. El legado Villaescusa. Adquisiciones 1992-1993, (Madrid: Museo del Prado, 1993), pp. 32-35, no 7618.

3 ABC Cultural (26-XI-1993); Aida Padrón Mérida, "El mundo de los Osona. Atribuciones poco convincentes". Antiqvaria, 128, (1995), p. 67.

4 Diego Angulo Iñiguez, "Tres pinturas renacentistas valencianas", Archivo Español de Arte, 105, 27, (1954), pp. 69-70, lám. V.

${ }^{5}$ Chandler Rathfon Post, A history of Spanish Painting, XII, part II, (Cambridge: Mass Harvard Univ. Press, 1958), p. 755.

6 Felipe María Garín Ortiz de Taranco, Yáñez de la Almedina, pintor español, (Ciudad Real: Instituto de Estudios Manchegos, 1978), p. 135. 


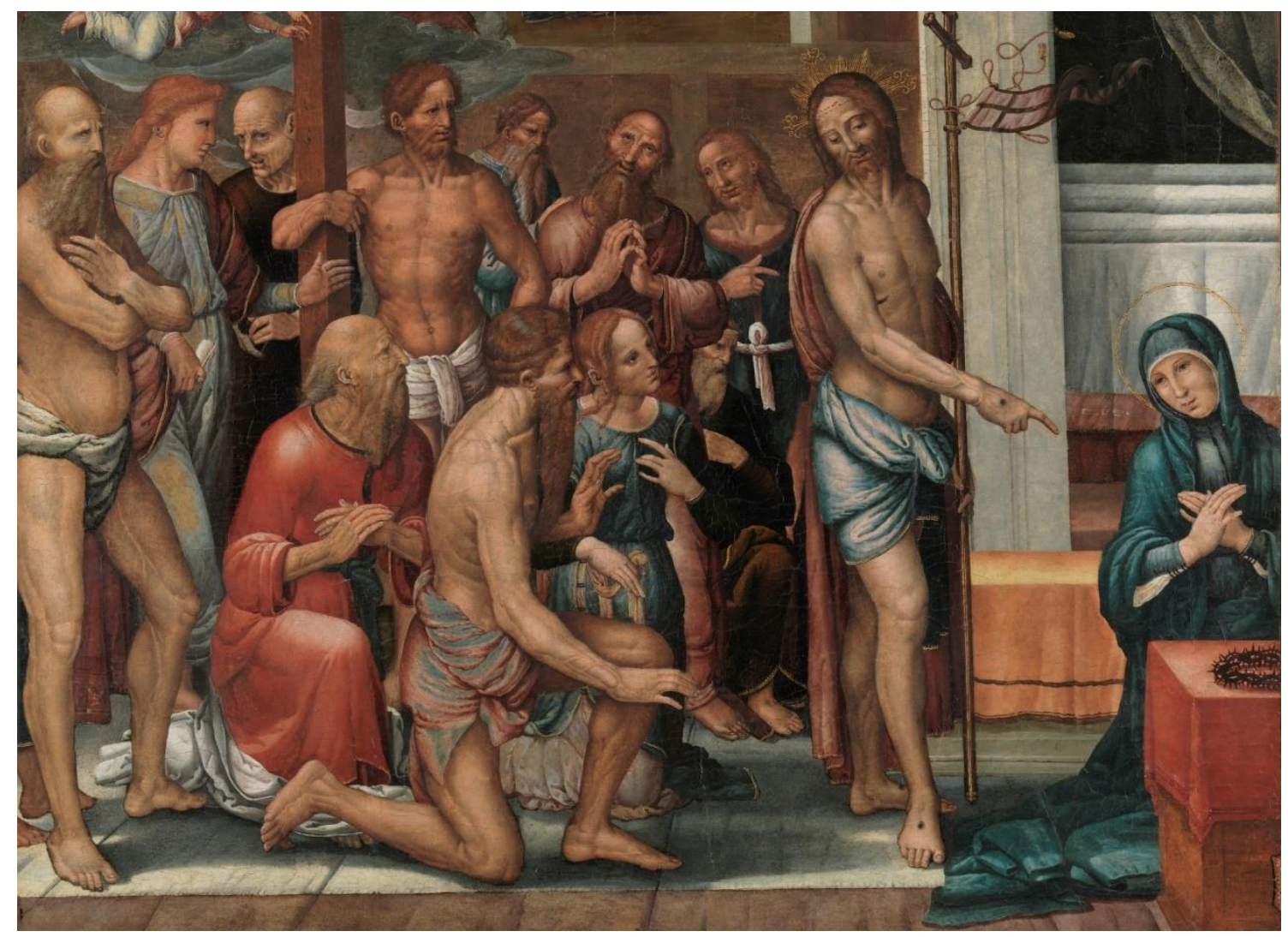

Fig. 1. Martín Gómez “el viejo” (aquí atribuida), Cristo presenta a la Virgen a los redimidos del Limbo, Museo del Prado (P07618), Madrid. Foto Museo del Prado@

Habrá que esperar a la adquisición de la obra por parte del Museo del Prado para una revisión sobre la autoría de la tabla. Pedro Miguel Ibáñez Martínez hará referencia a las distintas publicaciones sobre la pintura, desechando la atribución a Martín Gómez ya señalada de 1993. En distintos trabajos, la atribuye al taller de Yáñez, personificado en el Maestro del Grifo con escasa participación del maestro, que aporta la composición y fragmentos como la figura de Cristo y la de Adán en su mayor parte. La sitúa además en el período valenciano maduro del pintor, hacia 1518, año de su vuelta a Almedina: iniciada por el maestro, la deja en un estadio inicial siendo completada por su taller7. Por último, mucho más recientes son los trabajos de José Gómez Frechina y Vicente Samper Embiz, que insisten en la atribución a la última etapa valenciana de Yáñez, pero en solitario o con escasa participación de taller ${ }^{8}$.

La insistente catalogación a Yánez de la tabla de Cristo presenta a la Virgen a los redimidos del Limbo en distintas publicaciones exige la transcripción literal del texto alusivo del profesor Angulo: "Obra de calidad inferior al San

\footnotetext{
7 Pedro Miguel Ibáñez Martínez, "El período valenciano maduro de Fernando Yáñez", Archivo Español de Arte, 267, (1994), pp. 230-234; Fernando de la Almedina (La incógnita Yáñez), (Cuenca: Universidad de Castilla La mancha, 1999), pp. 393-396; La huella de Leonardo en España. Los Hernando y Leonardo, (Madrid: Canal de Isabel II, 2011), pp. 12-13 y pp. 334-349.

8 Vicente Samper Embiz, "La única Primera Aparición del Prado. Reivindicando una obra de Yáñez", Ars Longa, 22, (2013), pp. 99-109.
} 
Miguel de Orihuela, pero que no encuentro reproducida por Post ni por Garín y que merece serlo, es la tabla de El Salvador presentando los patriarcas a la Virgen (...). A juzgar por su estilo cansado y no poco seco, mucho más próximo a la Crucifixión de Cuenca que al retablo de la Catedral de Valencia, parece que debe pensarse en una etapa bastante tardía de su carrera". En esta objetiva afirmación se manifiestan las reservas de su autor y la validez de sus afirmaciones. El párrafo anotado es resultado de una meditada observación, ya que, en páginas escritas probablemente con anterioridad, pese a la coincidencia de las fechas de publicación, expresó una mayor convicción en su atribución al pintor: "Este estilo tardío y cansado de la Crucifixión de Cuenca, creo que es también el de los Juicios Finales de Játiva y Mallorca, el Salvador con los Patriarcas y la Virgen de la colección Adanero, de Madrid, y alguna otra obra"'.

Evidentemente, el cómputo global de los caracteres pictóricos revalidan su inclusión en el taller o círculo de Yánez, e incuestionablemente también en relación directa con su labor tardía en Cuenca. Esta pintura de compleja autoría inmersa, incuestionablemente, en la médula del arte de Yánez, transpira, sin embargo, un clima foráneo que avala su admisión en la estela de seguidores conquenses y su restitución, en concreto, a Martín Gómez "el Viejo", pintor de la catedral de Cuenca hasta 1562, año en que le sucede en el cargo su hijo Gonzalo Martín. El colorido, las sombras y el expresionismo incontenible de los modelos perfilan notas de índole personal, que aunque conjugados al léxico yañezco, se apartan de la solemne concepción formal del maestro. La abigarrada agrupación de modelos, en un interior de arquitectura de insinuación simplista (sin vacíos intermedios que sugieran la ruptura del plano y la evocación interminable del espacio en profundidad) revela una constante de la producción de Martín Gómez. Los rostros desencajados y el modelado duro distan de la evanescente realidad y de la melancolía anímica de Yánez. Los movimientos alternantes de las cabezas, inclinadas a derecha e izquierda, o en riguroso perfil, diferencian esta composición de la frontal agrupación yañezca. Lo mismo sucede con el imponente aplomo arquitectónico que imprime a sus modelos: aquí, en cambio, se reproduce el mismo variable ceremonial que, lejos de la inmutable firmeza del almedinense, se complace en las inestables actitudes que produce el exonerar la pierna izquierda del peso unitario del cuerpo. Las sensibles diferencias se incrementan con la enfática articulación gestual de las manos, destacadas en posición preferente. En comparación, el canon de las figuras resulta más largo y desgarbado en Martín Gómez, que resuelve además las peculiaridades anatómicas en una escritura en relieve ajena a Yáñez: deforma los esternocleiodomastoideos en un triángulo invertido, de ancho reborde, y la circulación venosa en un recorrido ornamental que surca, de forma consistente y llamativa, la epidermis como en una talla escultórica. Las

9 Diego Angulo Iñiguez, Ars Hispaniae, XII, Pintura del Renacimiento, (Madrid: ed. Plus-Ultra, 1954), p. 51. 
sombras pierden el carácter de transparente neblina de Yáñez, y los cuerpos semidesnudos se muestran en su tangible crudeza marmórea.

El contenido iconográfico rememora las eruditas connotaciones literarias del culto y devoto ambiente de la época. El pintor traduce en su obra un sentimiento popular inflamado por el impacto de los sermones y de la meditación dirigida desde el púlpito. El desarrollo de la imprenta divulgó el significado de la palabra por medio de la imagen, e influyó en el ámbito valenciano precedente. El Maestro de Perea representó el mismo asunto en el retablo del Museo de Bellas Artes de Valencia, que Post interpretó en relación directa con los escritos de Sor Isabel de Villena, abadesa del convento de la Santísima Trinidad entre 1463 y $1490^{10}$. Su Vita Christi, editada por primera vez en 1497, abarca la cronología terrenal de Jesús, incluyendo la Asunción de María ${ }^{11}$. Post recuerda en esta misma relación la anónima Égloga a la Resurrección, que se publica en Burgos en $1520^{12}$. Leandro de Saralegui en sus Remembranzas Vicentinas argumenta su correspondencia con los sermones de San Vicente Ferrer ${ }^{13}$. Impresos por primera vez en 1475 en Ulm, "los sermones vicentinos formaban con todas estas obras y otras muchas de materias análogas, el conjunto editorial que exigía el mercado internacional que llenaban los armarios de las celdas conventuales y las bibliotecas catedralicias"14; la popularidad debida a la imprenta explica el ancho margen geográfico de esta representación que no queda, como se ha dicho, restringida a Valencia. Leandro de Saralegui reproduce el sermón del 23 de Abril de San Vicente que dio vida, en su opinión, a estas tablas de devoción ${ }^{15}$. Estos escritos debieron incentivar el culto en la región, pero no hay que olvidar la repercusión en la iconografía internacional de narraciones de Jacopo de la Vorágine en la Leyenda Dorada. Saralegui registra otras tablas valencianas del mismo asunto a nombre del Maestro de Castellnovo en la Galería Siberman de Nueva York; del Maestro

10 Post, History of Spanish painting, VI, part I, (Cambridge: Mass Harvard Univ. Press, 1935), pp. 270272, fig. 104.

${ }^{11}$ El episodio se describe en los capítulos CCXXXVII-CCXXXIX, en la edición de R. Miquel y Planas, 1916, vol. III, pp. 164-179.

12 Post registra esta información en el volumen citado de su corpus e informa de otras publicaciones al respecto. Post, History of Spanish, VI, part. I, p. 270, nota 1.

13 Leandro de Saralegui, "Miscelánea de remembranzas vicentinas", Archivo de Arte Valenciano, 26, (1955), pp. 5-32.

${ }^{14}$ Felipe Mateu i Llopis, "La iconografía tipográfica de San Vicente", Archivo de Arte Valenciano, 26, (1955), p. 41. Enumera la cronología y sede de las sucesivas publicaciones de estos sermones.

15 "Cascú per son Orde... Adam ab los Sants patriarques...Aprés ve le santa Eva, que santa fo per gran penitencia, e Sara e Rebeccha... Santa Anna e Elisabetha... la gloriosa resurreció fo demostrada, primo a la Verge María, Sent Ambrós expresse ho diu... los evangelistas non dien res, que no 'u curaren; axi com en un procés han dat sos testimonis e no' y han mes la mare per testimoni. La primera rahó per que aparech primer a la Verge fonch per complir Ço que havia manat de honrar pare e mare... Secunda racio... per que tots los apostols e dexebles, lo dia de la passió perderen la fe xpistiana... duptant si es, no es; mas en la Virge ferma hi fon la fé... la terca rahó... Seguidamente narra cómo al verlo entrar". Saralegui, "Miscelánea", p. 10. 
de San Lázaro en la colección A. Lehman de Nueva York; y de Miguel Esteve, en la colección Cluet de Georgia ${ }^{16}$.

Knipping explica el eco de este asunto, de procedencia hispana, en la iconografía flamenca, fruto del debate espiritual de San Ignacio de Loyola ${ }^{17}$. El boceto de Gerard Seghers en la colección Koetser y las versiones del Museo Plantin Moretus de Amberes y colecciones privadas de Nueva York y Madrid prueban la persistencia del tema en el siglo XVII ${ }^{18}$, y la respuesta católica a la Reforma, contraria al sacramento de la Penitencia ${ }^{19}$.

La Leyenda Dorada detalla en un amplio capítulo la aparición de Cristo resucitado a María y su bajada al Limbo ${ }^{20}$. Menciona como confirmación distintas fuentes, como el Libro Sobre las Vírgenes de San Ambrosio y los poemas de Sedulio; el Evangelio de Nicodemo, los sermones de San Agustín y "el libro que unos atribuyen a Gregorio Niseno y otros a San Agustín"21.

Las fuentes literarias permiten conocer la identidad de los presentes: se menciona a Carino y Leucio, hijos de Simeón; a Adán, Simeón, Isaías, San Juan Bautista, Seth, Enoch, Elías y Dimas (Nicodemo incluye a David en este elenco nominal), pero estas personalidades no se distinguen con ningún atributo en la tabla de estudio. El texto más claro señala a Dimas en el personaje que, como émulo de Cristo, destaca de pie apoyado en el madero de una cruz:

"Más adelante se encontraron con otro que llevaba sus hombros marcados con una cruz. Él respondió: soy aquél ladrón que fue crucificado con Cristo. Antes de morir reconocí que era el Creador, creí en Él, lo adoré, y le dije: iSeñor, acuérdate de mí cuando estés en tu reino!, y Él me contestó: Te aseguro que hoy mismo estarás conmigo en el Paraíso. Luego me marcó con esta señal de la cruz [...] y me colocó en esta parte derecha del Paraíso"22.

Probablemente el personaje arrodillado ante Cristo sea Adán, estirpe de la raza humana, que asume obviamente un papel destacado en este episodio del Descenso de Cristo al Limbo: "Abrió éste la puerta del cielo, franqueó la entrada a Adán y tras Adán entraron también los santos padres que formaban el espléndido cortejo"23. El joven que figura al lado de Adán podría

\footnotetext{
${ }^{16}$ Ibidem, p. 11.

17 John Baptist Knipping, Iconography of the Counter Reformation in the Netherlands. Heaven on earth, I, (Leyden: De Graaf, 1974), p. 194. Reseña la tradición de Molanus en relación a esta iconografía.

18 Matías Díaz Padrón, "Dos bocetos de Thomas Willeboerts Boschaert y de Gerard Seghers en el Museo de Picardie y colección Koetser", Archivo Español de Arte, 209, 53, (1980), pp. 19-26.

19 Emile Mâle, L'Art religeux aprés le Concile de Trente. Etude sur L'Iconographie de la fin du XVIe siècle, du XVIIe, du XVIIIe siècle. Italie--France--Espagne--Flanders, (Paris: Librairie Armand Colin, 1932), p. 71.

20 Jacopo de la Vorágine, La Leyenda Dorada, I, (Madrid: Alianza, 1982), pp. 233-235.

${ }^{21}$ Ibidem, p. 235.

22 Ibidem, p. 235.

23 Ibidem, pp. 234-235.
} 
representar a su hijo Seth, portador en estas narraciones del mensaje de su padre a la humanidad. La singularidad física y la serena complacencia del anciano, barbado y semidesnudo, que cierra la composición en el lateral izquierdo de la tabla, coincide con la descripción de San Juan Bautista: "A continuación pidió la palabra un anacoreta; antes de que empezara a hablar le rogamos que nos dijera quién era y nos dijo: Yo soy Juan, yo fui delante de Él preparando sus caminos (...) y cuando descendí aquí comuniqué a todos que no tardaríamos en recibir su visita"24. El juvenil aspecto del modelo que viste túnica talar y manto, y que sostiene un pergamino enrollado en la mano derecha, confirma que se trata de la figuración simbólica de Carino y Leucio, relatores de la visita de Jesús al Limbo en el Evangelio de Nicodemo: "Les hicieron señas con las manos para que les dieran un rollo de papel y tinta. Y lo hicieron así porque el Espíritu Santo no les permitió hablar con ellos. Estos le dieron el papel a cada uno y les separaron entre sí en distintos compartimentos $^{\prime 25}$. La presencia en la pintura de sólo uno de los dos hermanos se explica porque ambos escribieron, sin variantes, el mismo mensaje: "Reunido de nuevo el consejo, se leyó íntegramente el otro escrito (el volumen de Leucio) y no se encontró en él ni más ni menos, ni siquiera con relación a una sola letra, que lo que contenía el escrito de Carino"26. No se ha podido reconocer el objeto que revelaría la personalidad del sujeto, de identidad por ahora anónima, representado a la izquierda de Leucio y Carino; sin embargo, los datos apuntan hacia Simeón, padre de los gemelos, que circuncidó a Jesús en su infancia ${ }^{27}$. Los profetas se reconocen por exclusión en el grupo de varones de luengas barbas que, en actitud orante o reconcentrada, se sitúan en el fondo, a la derecha inmediata de Cristo. Esta extensa galería de patriarcas y profetas, vinculados real o figuradamente a la genealogía de Cristo, reemplaza la amplia presencia femenina en la versión del Limbo del Maestro de Perea, influida directamente por el prólogo de Vicente Ferrer a su sermón del Domingo de Pascua.

En esta composición confluyen préstamos de los maestros renacentistas del mundo nórdico e italiano. El San Juan Bautista se inspira, a través del grabado, en el San Onofre de Durero de la Kunsthalle de Bremen; la postura de Adán recuerda al San Juan Bautista del Bautismo según grabado de Marcantonio Raiomondi en Viena ${ }^{28}$. Si Yáñez asumió aportaciones rafaelescas y motivos de Miguel Ángel en su labor pictórica de Cuenca, Martín Gómez recibió también aquí estímulos del arte de Miguel Ángel: la figura de Dimas apoyada en la cruz evoca, transformado, el concepto del Cristo Resucitado de Santa María Sopra Minerva.

\footnotetext{
24 Ibidem, p. 234.

25 Evangelio de Nicodemo I (XVII), 8. Evangelios Apócrifos. Estudios introductorios y versión de los textos originales de Aurelio de Santos Otero, (Madrid: B.A.C, 2005), p. 239.

26 Evangelio de Nicodemo XI (XXVII). Ibidem, p. 245.

27 Quizás represente un motivo, relacionado con las escribanías, que refuerce la validez y autenticidad del manuscrito de sus hijos Carino y Leucio.

28 The illustrated Bartsch, 26, Vol. 14, Part 1, (Nueva York: Abaris Books, 1978), 22-I (28), p. 35.
} 
Las tipologías derivan de Yáñez, "que tantos ecos despertó entre nuestros artistas, y aún más que ningún otro en el propio Martín, debemos considerar a este último el más grande los pintores conquenses del Renacimiento"29. La congregación de los tres patriarcas en el fondo de la composición retiene, y de ellos se coligen las diferencias, la imagen de los representantes del Sanedrín de la Catedral de Cuenca. El pastor de Yáñez, en la versión del Abrazo ante la puerta dorada de la catedral de Valencia, se diferencia de la figura decorativa de Cristo que sostiene grácilmente su estandarte; el zagal de Yáñez apoya virtualmente su peso, con aire cansino, en la vara. La firmeza del cuello y el perfil de nariz recta de Carino reproduce los rasgos del arcángel en la Anunciación de Yáñez en el Colegio del Patriarca de Valencia. En suma, los tipos de Martín Gómez son una "literal repetición de figuras, que el maestro almediense había empleado anteriormente en sus obras" ${ }^{\prime 30}$, pero el rostro de María, apretado y lineal, se desprende del repertorio humano de Yáñez: los ojos menudos, el mentón marcado y los labios prietos reflejan un ideal de belleza netamente diferenciado de la suave ensoñación de la Santa Catalina del Museo del Prado. La dureza que subraya las líneas en el rostro aniñado de Seth, indica la disparidad técnica de Martín Gómez respecto al ángel del maestro del Juicio Final de Játiva o en la Virgen de la Sagrada Familia del Prado. El anciano arrodillado en segundo término, a espaldas de Cristo, parece transmutar el rostro del apóstol, que abandona la cámara de María en el Tránsito de Yáñez de la catedral de Valencia. La cabeza que asoma en escena junto al madero que simboliza a Dimas recuerda al apóstol sumido en la lectura de un breviario en la composición citada del Tránsito de María. El tratamiento muscular y óseo de Martín Gómez refleja sus disensiones con el maestro. Además de las notas ya comentadas, se deleita en el pronunciado efecto plástico de los arcos superciliares y los cartílagos nasales. En un forzado análisis de comprensión manierista, las manos dibujan un anómalo pliegue anular en la base del dedo meñique, e insiste en las malformaciones del pabellón auditivo externo. Rompe su diseño, prácticamente semicircular, en un saliente agudo. Basta recordar por último que Yáñez relega a los planos secundarios los signos de decrepitud humana, y Martín Gómez, por el contrario, los destaca en términos protagonistas.

No resulta fácil de acotar (aún a pesar del positivo balance de las investigaciones de Pedro Ibáñez), la obra autógrafa de Martín Gómez en la intrincada red que proyectan sus continuas colaboraciones en retablos de la zona; además, las obras de calidad mediocre y dudosa filiación que figuran a su nombre dificultan todavía más la sistematización de su catálogo. La obra genuina de Martín Gómez se resiente con la intervención documentada de Gonzalo y Pedro de Castro en el retablo de Valdecabras. La ósmosis estilística que resulta inevitable en los trabajos mancomunados lo es, aún más, en

\footnotetext{
29 Pedro Miguel Ibáñez Martínez y Carmen Pérez García, El retablo de Valdecabras, (Cuenca: Ayuntamiento y Diputación de Cuenca, 1984), p. 63.

30 Pedro Miguel Ibáñez, Los Gómez, una dinastía de pintores del Renacimiento, (Ciudad Real: Universidad de Castilla La Mancha, 1991), p. 116.
} 
Martín Gómez, cuya receptividad a Yáñez verifica la permeabilidad de su carácter. Idéntica problemática presenta el Retablo de la Asunción de la Capilla Barreda de la catedral de Cuenca, en colaboración, según Ibáñez, con Gonzalo Gómez.

Al margen de la participación conjunta, y aún en demérito de su estilo, de Martín Gómez con sus contemporáneos de formación provinciana, reconocemos en las pinturas catalogadas a su nombre unas características que fijan, al mismo tiempo, su paternidad en la tabla de Cristo resucitado y los Patriarcas del Limbo. En la Presentación de Jesús en el templo, del Museo Diocesano de Cuenca, advertimos la misma peculiaridad, observada ya en la tabla de estudio, en la forma de sostener el cirio: fórmula que se repite en el San Mateo y San Lorenzo de la catedral de Cuenca y en la manera inusual con que Carino y Leucio sostienen el manuscrito, o Cristo el estandarte de la cruz. El perfil del sumo sacerdote en la Presentación del Museo Diocesano se reproduce en el Martirio de San Juan Evangelista del Museo Catedralicio (obra ésta de técnica más descuidada) y en el muestrario de modelos en estudio que, a pesar de los cambios de actitud, edad o vestimenta, no transfigura los rasgos esenciales. Las facciones del San José de la Visitación, que se identifica prácticamente en busto entre Zacarías y María, son idénticas en Simeón, que se entromete tímidamente en esta escena entre Dimas y Carino. El rostro de María se repite en el joven Seth.

En las obras registradas, en líneas precedentes, se acumulan como aquí idénticos conceptos: la distribución abigarrada y asfixiante de los modelos en el espacio; la algarabía dialogante de las manos; los tipos y la configuración anatómica; los rostros ceñudos; la forzada separación del meñique, y la confrontación de las sombras y los motivos de concepción lineal. El mimetismo, hiriente en la repetición de los rictus, revela diferencias sustanciales en esta obra dependiente, como la Presentación de Jesús en el templo, del maestro de la Almedina. Las deficiencias en el análisis de la estructura ósea, que acentúan el abismo entre esta obra y la de Yáñez, se perciben en la caída hacia delante de la cabeza del profeta en oración suplicante, y en el patriarca que rinde homenaje a Cristo detrás de Adán. El oro líquido del nimbo y las orlas de los mantos subrayan su compromiso con la región valenciana; lo mismo indica el diseño listado, de origen morisco, en la vestimenta de Seth. 


\section{BIBLIOGRAFÍA}

Angulo Íñiguez 1954: Diego Angulo Íñiguez, "Tres pinturas renacentistas valencianas", Archivo Español de Arte, 105, 27, (1954), pp. 69-70.

Angulo Íñiguez 1954: Diego Angulo Iñiguez, Ars Hispaniae, XII, Pintura del Renacimiento, (Madrid: ed. Plus-Ultra, 1954).

Apócrifos ed. 2005: Evangelios Apócrifos. Estudios introductorios y versión de los textos originales de Aurelio de Santos Otero, (Madrid: B.A.C, 2005).

Bartsch: The illustrated Bartsch, 26, Vol. 14, Part 1, (Nueva York: Abaris Books, 1978).

De la Vorágine 1982: Jacopo de la Vorágine, La Leyenda Dorada, I, (Madrid: Alianza, 1982).

De Saralegui 1955: Leandro de Saralegui, "Miscelánea de remembranzas vicentinas", Archivo de Arte Valenciano, 26, (1955), pp. 5-32.

Díaz Padrón 1980: Matías Díaz Padrón, "Dos bocetos de Thomas Willeboerts Boschaert y de Gerard Seghers en el Museo de Picardie y colección Koetser", Archivo Español de Arte, 209, 53, (1980), pp. 19-26.

Garín Llombart 1993: Felipe Vicente Garín Llombart, Un mecenas póstumo. El legado Villaescusa. Adquisiciones 1992-1993, (Madrid: Museo del Prado, 1993), pp. 32-35.

Garín Ortíz de Taranco 1978: Felipe María Garín Ortiz de Taranco, Yáñez de la Almedina, pintor español, (Ciudad Real: Instituto de Estudios Manchegos, 1978).

Ibáñez Martínez 1991: Pedro Miguel Ibáñez, Los Gómez, una dinastía de pintores del Renacimiento, (Ciudad Real: Universidad de Castilla La Mancha, 1991).

Ibáñez Martínez 1994: Pedro Miguel Ibáñez Martínez, "El período valenciano maduro de Fernando Yáñez", Archivo Español de Arte, 267, (1994), pp. 225242.

Ibáñez Martínez 1999: Pedro Miguel Ibáñez Martínez, Fernando de la Almedina (La incógnita Yáñez), (Cuenca: Universidad de Castilla La mancha, 1999), pp. 393-396.

Ibáñez Martínez 2011: Pedro Miguel Ibáñez Martínez, La huella de Leonardo en España. Los Hernando y Leonardo, (Madrid: Canal de Isabel II, 2011).

Ibáñez Martínez y Pérez García 1984: Pedro Miguel Ibáñez Martínez y Carmen Pérez García, El retablo de Valdecabras, (Cuenca: Ayuntamiento y Diputación de Cuenca, 1984).

Knipping 1974: John Baptist Knipping, Iconography of the Counter Reformation in the Netherlands. Heaven on earth, I, (Leyden: De Graaf, 1974). 
Mâle 1932: Emile Mâle, L'Art religeux aprés le Concile de Trente. Etude sur L'Iconographie de la fin du XVIe siècle, du XVIIe, du XVIIIe siècle. Italie-France--Espagne--Flanders, (Paris: Librairie Armand Colin, 1932).

Mateu i Llopis 1955: Felipe Mateu i Llopis, "La iconografía tipográfica de San Vicente", Archivo de Arte Valenciano, 26, (1955), pp. 33-49.

Padrón Mérida 1995: Aida Padrón Mérida, "El mundo de los Osona. Atribuciones poco convincentes", Antiqvaria, 128, (1995), pp. 66-75.

Post 1935: Chandler Rathfon Post A History of Spanish Painting, VI, part I, (Cambridge: Mass Harvard Univ. Press, 1935)

Post 1958: Chandler Rathfon Post, A History of Spanish Painting, XII, part II (Cambridge: Mass Harvard Univ. Press, 1958).

Samper Embiz 2013: Vicente Samper Embiz, "La única Primera Aparición del Prado. Reivindicando una obra de Yáñez", Ars Longa, 22, (2013), pp. 99-109. 